\title{
Comparative Analysis of Optical Signals Emitted by Corona on a Laboratory Model of Transmission Lines Made of Various Materials
}

\author{
Sławomir Krzewiński, Paweł Frącz, Ireneusz Urbaniec, and Tomasz Turba \\ Faculty of Electrical Engineering, Automatic Control and Computer Science, Opole University of Technology, Prószkowska 76, \\ 45-758 Opole, Poland
}

Correspondence should be addressed to Paweł Frącz; pawelfracz2@gmail.com

Received 29 September 2016; Revised 8 December 2016; Accepted 18 December 2016; Published 15 March 2017

Academic Editor: Khalique Ahmed

Copyright (c) 2017 Sławomir Krzewiński et al. This is an open access article distributed under the Creative Commons Attribution License, which permits unrestricted use, distribution, and reproduction in any medium, provided the original work is properly cited.

\begin{abstract}
The paper presents results of comparative analyses of optical signals generated by corona discharges occurring in the vicinity and on the surface of power transmission lines made of five different materials under laboratory conditions. Three aluminium-based materials were chosen: pure aluminium, aluminium with added magnesium, and aluminium with added silicon, and for comparison purposes also, steel-based lines were considered: copper-coated steel and steel with added chromium and nickel. A three-phase triangular arrangement system operating under maximal voltage equal to $110 \mathrm{kV}$ was applied for experimental tests. The optical radiation was registered using a spectrophotometer. During research works, also the influence of corona generation voltage and distance between power lines was investigated. Based on the achieved results, it was stated that the highest corona intensity was found for aluminium-based lines, for both pure aluminium and aluminium with added magnesium and silicon. The lowest corona intensity was observed for chromium- and nickel-alloyed (stainless) steel.
\end{abstract}

\section{Introduction}

Extra high voltage power transmission lines $(220,400$, and $750 \mathrm{kV})$, high voltage lines $(110 \mathrm{kV})$, and distribution lines along with power plants and substations form the main elements of a power system, the purpose of which is to produce and transmit energy to individual consumers. Interruptions in electricity supply especially to industrial consumers can lead to substantial financial losses. Thus, all components of the power system should work stably, reliably, and at the lowest possible cost. In situations which may cause a failure, the response time should be as short as possible; therefore, it is necessary to use in the power equipment state-of-the-art automated protection instruments $[1,2]$.

Three-phase power transmission lines are usually supplied from the sources located in power plants. Operation of power transmission lines is associated with energy losses which generate additional costs to the system. The main reason for these losses is heat generation caused by the flow of current. While maintaining the desired power, the current may be reduced by increasing at the same time the voltage value. Therefore, in order to minimize electricity losses, lines for extra high voltages are constructed. This in turn results in the increase of the costs of other system components including insulators, cables, accessories, and support structures. Another issue connected to energy losses during operation of power transmission lines, especially under extreme conditions at high humidity and temperature, is generation of corona discharges in the vicinity of power line [3-6]. There exist various methods for detection and localization of corona discharges [7-10]. In research studies, the results of which are presented in this paper, corona discharges occurring on a laboratory model of power transmission lines made of various materials were registered using optical spectrophotometry. In particular, a triangular arrangement of lines supplied with a rated 


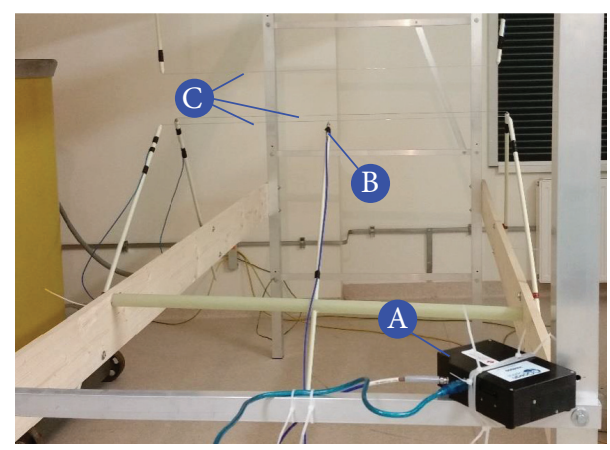

Figure 1: General view of the test station in laboratory: A, spectrophotometer, B, head of the fibre optic cable which transmits optical signal to the spectrophotometer, and C, power transmission lines.

voltage of $110 \mathrm{KV}$ was considered and implemented under laboratory conditions.

The main contribution of this paper lies in the presentation of the impact of material type on the recorded optical spectra emitted by the laboratory setup of a power line. Also, the influence of supply voltage value and the distance between the lines arranged in the triangular system on the optical spectra was determined.

In the subsequent sections of this paper, the following is presented: the measurement system and research methods are presented in Section 2, the most crucial results of the conducted comparative analyses are presented in Section 3, and a discussion of the achieved findings is listed in Section 4. Section 5 summarizes the conducted studies and suggests possible future research.

\section{Methodology and Experimental Setup}

The studies involved registration of optical spectra generated by corona discharges occurring in the vicinity and on the surface of power transmission lines made of various materials. The constructed test station allowed for the reproduction of a power transmission line system in its simplified form, giving focus on mapping a triangular arrangement of the power lines. The general view of the test station depicted by spectrophotometry, which was applied for the measurement of optical radiation, the optical cable with the measuring head, and the arrangement of applied power lines, is presented in Figure 1. In Figure 2, an approximated view of the fibre optic cable head installed at a small distance to the power line is presented. The radiation was captured by the measuring head and transmitted to the spectrophotometer via the fibre optic cable.

The chief aim of the research was to analyze power lines made of various materials. During the planning process of the experimental studies presented here, the following criteria were considered: the analyzed materials should be commonly applied in the industry and relatively easily accessible for purchase, their chemical composition should be known, and they should have the same diameter. Therefore, three aluminium-based materials were chosen, and for comparison purposes also steel-based lines were considered. The types of

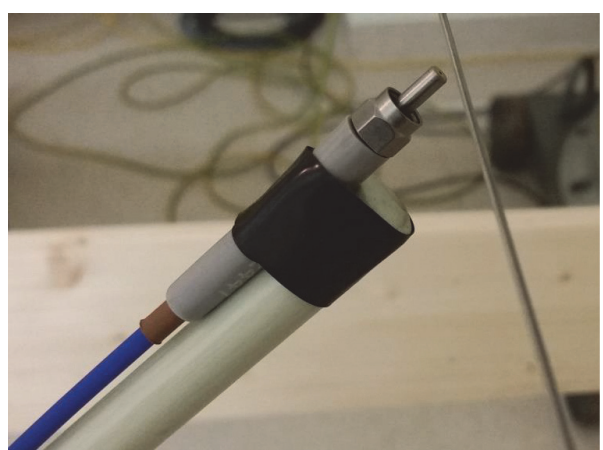

Figure 2: View of the fibre optic cable head used for the measurement of emission spectra generated by corona discharges.

materials, the applied designation, and their chemical composition are summarized in Table 1.

The experimental methodology involved the construction of a three-phase power transmission line model of a triangular arrangement wherein the power lines were made of the considered materials. The object under study was supplied from three independent transformers of rated power 220/110000 V generating AC voltage. The interfacial system breakdown voltage $U_{\mathrm{p}}$ was determined by changing distance $d$ between the power lines from $8 \mathrm{~cm}$ to $36 \mathrm{~cm}$, with a $2 \mathrm{~cm}$ step. For each experimental trial, values of the applied interfacial voltage were determined as derivatives of the breakdown voltage following the rule $0.9 U_{\mathrm{p}}, 0.8 U_{\mathrm{p}}, 0.7 U_{\mathrm{p}}$, and so on. For each value of the applied voltage and for each distance, the emitted optical spectra were registered with the spectrophotometer. The recorded results were subjected to comparative analysis, the results of which are presented in the next section.

The tested power transmission line arrangement was subjected to very intensive corona discharges that usually do not occur during normal operation of the power lines (e.g., operation at $90 \%$ of the line breakdown voltage), but on the other hand, the tests were performed under very favorable climate conditions-constant temperature of $23^{\circ} \mathrm{C}$ and relative humidity equal to approx. $30 \%$. Under actual operating conditions, the power line is subjected to varying temperatures, changing humidity, deposition of contaminations, soot, and so on $[11,12]$. All of these factors contribute to rather intensive corrosion and line degradation despite the lowest intensity of corona discharge occurrences.

Due to the highly stochastic nature of corona occurrence, as well as taking into account its impact on changes in the local physical and chemical parameters of the air, each measurement trial included registration of 30 samples. The aggregate comparisons lead to the conclusion that depending on the modified parameters of the test system, including distance between the power lines $(d)$ and corona generation voltage $\left(\% U_{\mathrm{p}}\right)$, differences of lesser or higher significance were observed in the particular spectra measured. For each measurement series, the registered intensity values were subjected for calculation of arithmetical mean, maximum, and minimum values. Significant differences were observed between the maximum and minimum values, which were not linearly dependent on discharge generation voltage nor 
TABLE 1: Designations and parameters of the materials used for production of tested models of power lines with a delta cable system.

\begin{tabular}{lcc}
\hline Designation & Line diameter, $\varphi$ & Type of material \\
\hline $\mathrm{Al}$ & $1.2 \mathrm{~mm}$ & Aluminium $99.5 \%$ \\
$\mathrm{AlMg} 5$ & $1.2 \mathrm{~mm}$ & Aluminium $94.4792 \%+$ magnesium $4.89 \%$ \\
$\mathrm{AlSi} 5$ & $1.2 \mathrm{~mm}$ & Aluminium $94.6751 \%+$ silicon $5.11 \%$ \\
$\mathrm{FeCu}$ & $1.2 \mathrm{~mm}$ & Copper-coated steel \\
$\mathrm{MIG} 308 \mathrm{LSi}$ & $1.2 \mathrm{~mm}$ & Chromium $19.6 \%+$ nickel $9.08 \%+$ manganese $1.85 \%+$ iron $68 \%($ stainless steel) \\
\hline
\end{tabular}

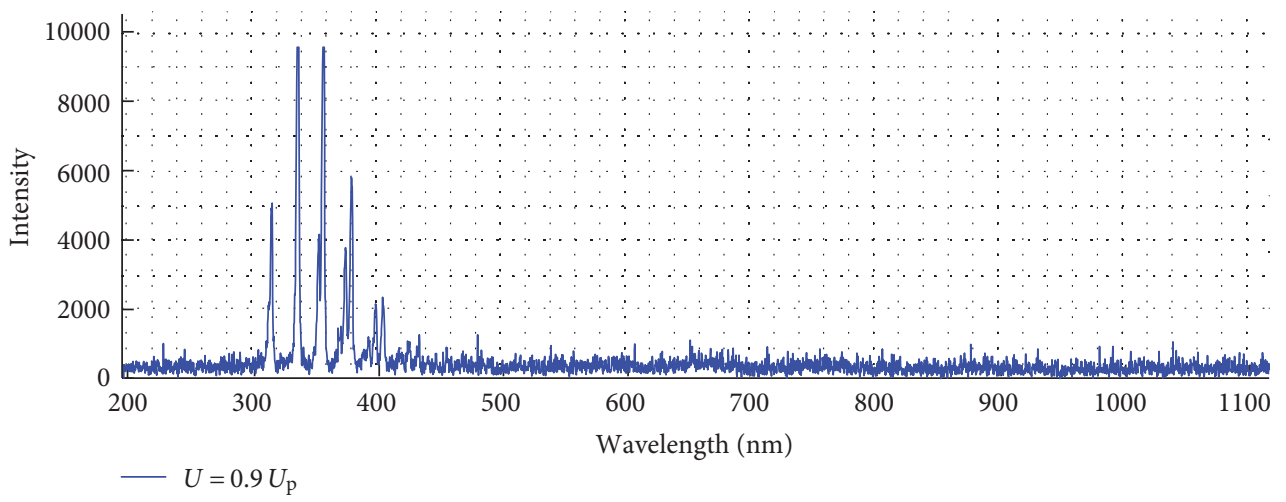

FIGURE 3: Optical spectrum registered in the vicinity of the aluminium line during measurements under voltage equal to $0.9 U_{\mathrm{p}}=109.1 \mathrm{kV}$ and distance $d=36 \mathrm{~cm}$.

on distance $d$. The further analysis focused on the mean and maximum values.

\section{Comparative Analysis of Measurement Results}

Figure 3 shows a typical measurement result of intensity of optical radiation emitted by the aluminium line during tests at a distance $d=36 \mathrm{~cm}$ and under supply voltage equal to $0.9 U_{\mathrm{p}}$, which relates to $109.1 \mathrm{kV}$.

As already mentioned in the section above, arithmetic averages were calculated for each measurement series. From the obtained averages for each voltage, for each distance, and for each type of the tested power line, the following parameters were determined:

(a) Energy of signal obtained as a sum of spectrum components in the entire analyzed range. The resulting number corresponds to the area under the spectral curve. The energy in this case is a conventional dimensionless unit determining the number of energy units for a given spectrum.

(b) Maximum spectrum values, that is, the highest intensities.

(c) The number of characteristics-significant frequency components of the spectrum; that is, the intensity was higher than 1600 .

The most important results of the comparative analysis are presented in the following subsections.
3.1. Comparative Summary for Signal Energy. Figures 4-8 present in aggregate the values of energy values calculated for average intensities of the emission spectra emitted at various corona generation voltages and various distances between power lines made of the considered materials: $\mathrm{Al}$, AlMg5, AlSi5, FeCu, and MIG308LSi.

3.2. Comparative Summary for the Number of Wavelength Components in the Intensity Spectra. Figures 9-13 present in aggregate the number of wavelength components included in the emission spectra of intensities exceeding the value of 1600. These values were calculated for averaged intensities registered by the analyzed generation voltages and distances between power lines made of the considered materials: $\mathrm{Al}$, AlMg5, AlSi5, FeCu, and MIG308LSi.

3.3. Comparative Summary for the Highest Intensities in Signal Spectra. Figures 14-18 present in aggregate the highest intensity values in the registered emission spectra. These values were calculated for averaged signals gathered by the regarded voltages and distances between power lines made of the considered materials: Al, AlMg5, AlSi5, $\mathrm{FeCu}$, and MIG308LSi.

\section{Discussion of Analysis Results}

Based on the analyses, it was concluded that the spectral intensity curves are similar for all types of power transmission lines. Furthermore, the shapes of the registered spectra resemble those obtained by spectrophotometry during emission of surface discharges on bushing and support insulators $[13-15]$ and on insulators made of porcelain and glass $[16,17]$. 


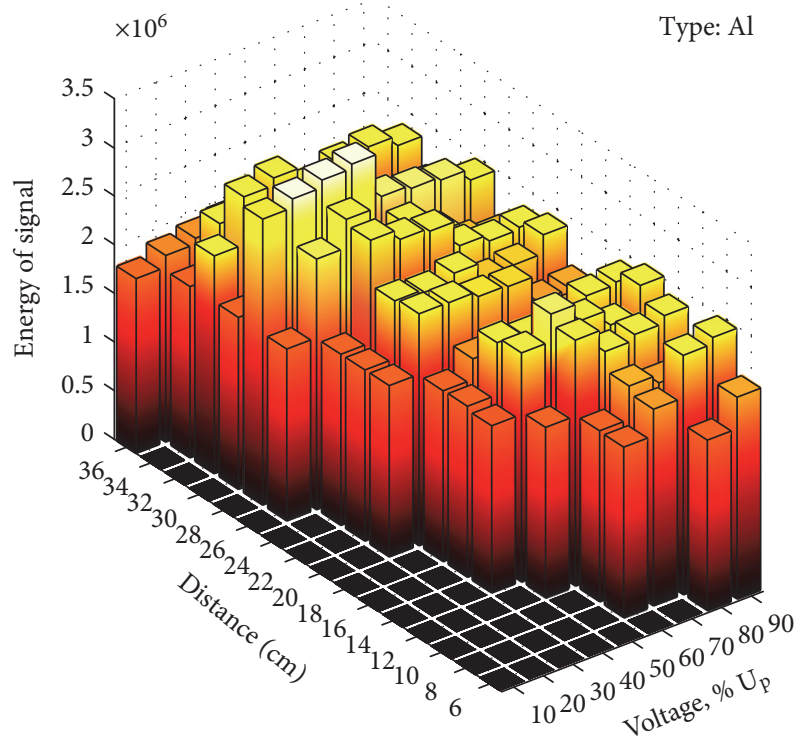

FIgURE 4: Dependency of voltage and distance on the value of energy of signal calculated for optical spectra emitted by corona around the $\mathrm{Al}$ line.

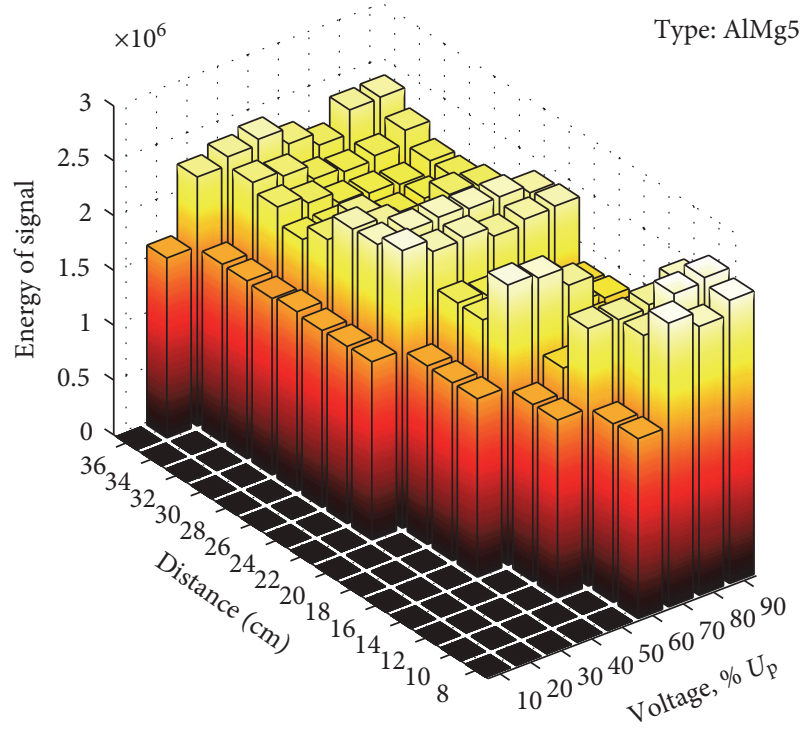

FIGURE 5: Dependency of voltage and distance on the value of energy of signal calculated for optical spectra emitted by corona around the AlMg5 line.

Below, the performed analyses and resulting conclusions are listed:

(i) The analysis of the wavelength components of intensities $I>1600$ was conducted for each type of power transmission line, for each supply voltage $\% U_{\mathrm{p}}$, and for distance $d$ between power lines. The obtained results led to the observation that characteristic wavelengths occur in the same ranges: $311-406 \mathrm{~nm}$, $425 \mathrm{~nm}, 434 \mathrm{~nm}, 481 \mathrm{~nm}, 652 \mathrm{~nm}$, and $1040 \mathrm{~nm}$.

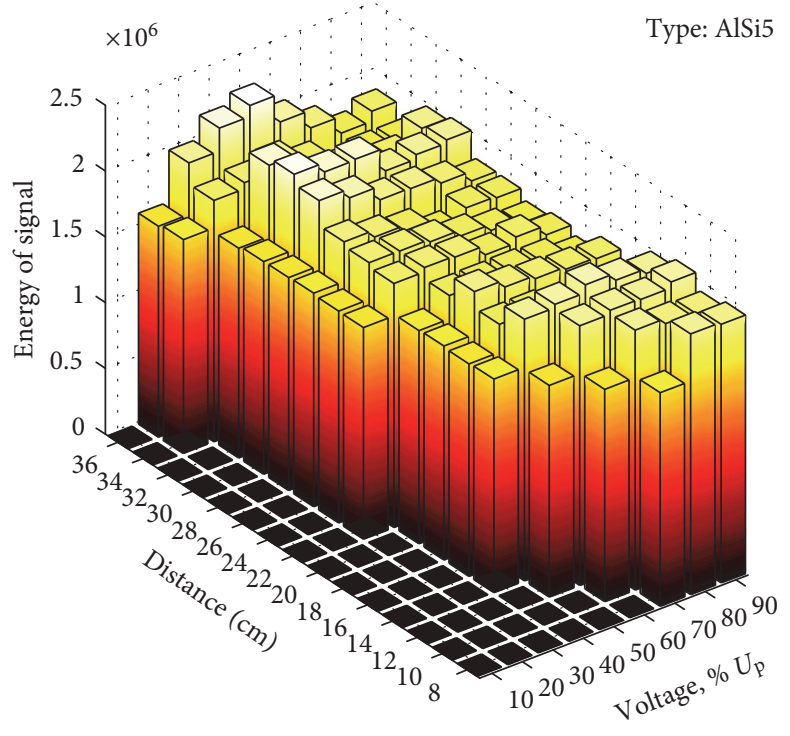

Figure 6: Dependency of voltage and distance on the value of energy of signal calculated for optical spectra emitted by corona around the AlSi5 line.

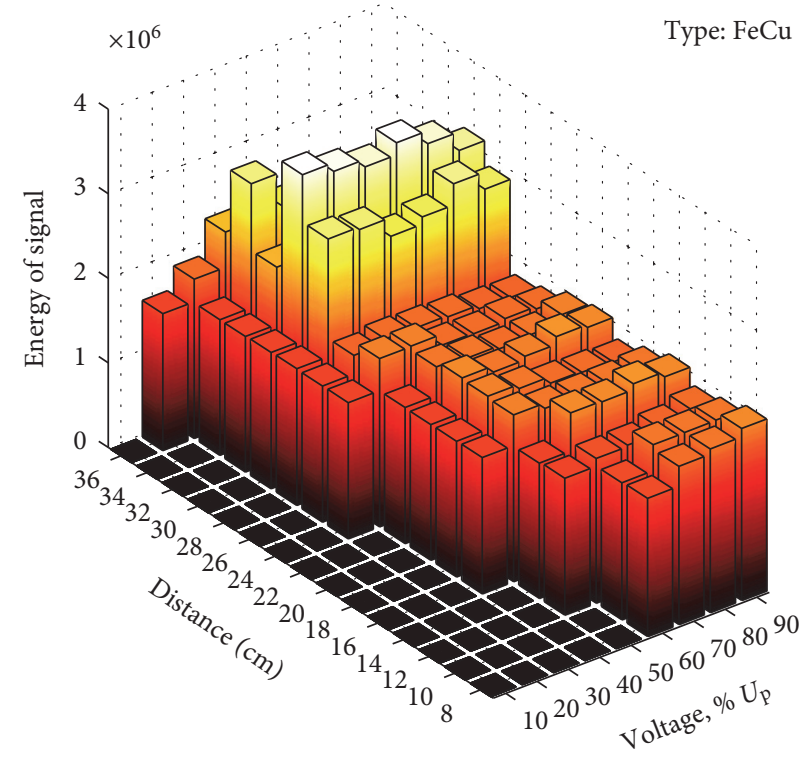

Figure 7: Dependency of voltage and distance on the value of energy of signal calculated for optical spectra emitted by corona around the $\mathrm{FeCu}$ line.

The occurrence of particular wavelengths changes for various generation voltages and distances $d$; however, no linear/monotonic relationships were found. This may lead to the conclusion that the observed wavelengths in the recorded spectra do not significantly depend on the material used for production of the power transmission lines.

(ii) The average intensities in the spectrum of each measurement series were used to calculate the area under 


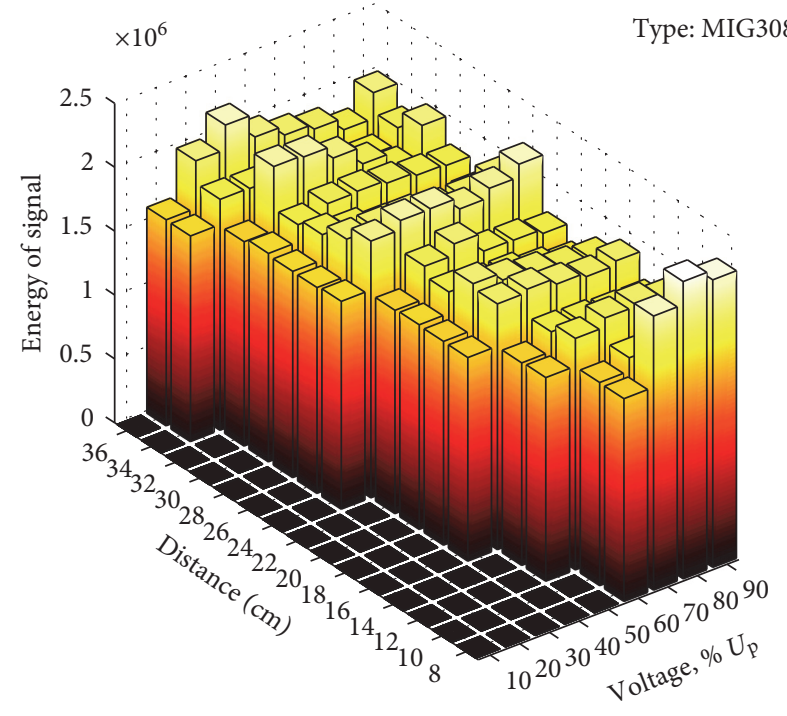

Figure 8: Dependency of voltage and distance on the value of energy of signal calculated for optical spectra emitted by corona around the MIG308LSi line.

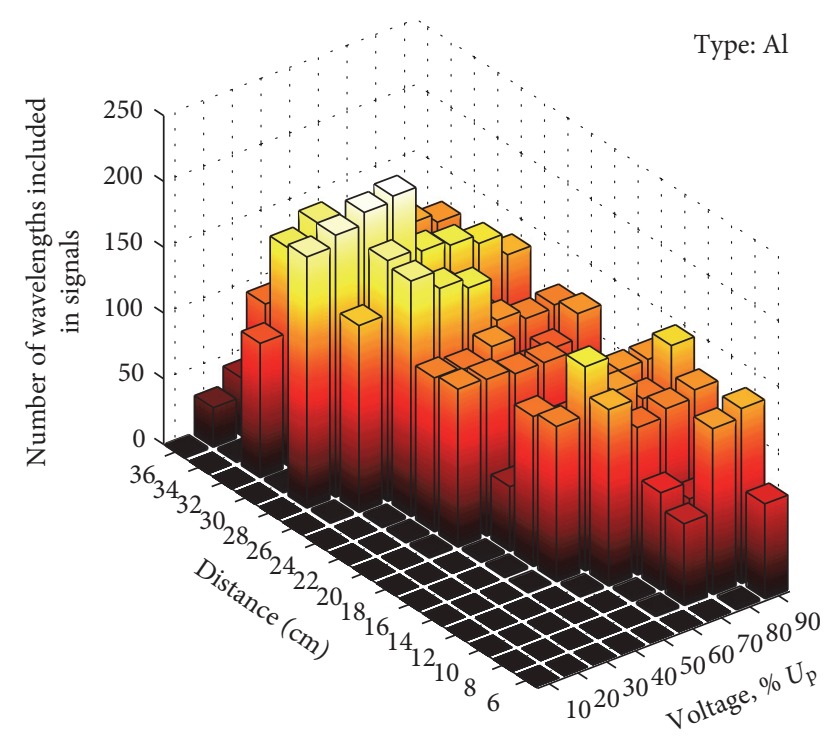

FIGURE 9: Dependency of voltage and distance on the number of wavelength components for the $\mathrm{Al}$ line.

the spectrum curve, denoted as signal energy. For each line type, a 3D graph was presented showing energy value as a function of distance $d$ and corona discharge generation voltage $\% U_{\mathrm{p}}$. This type of analysis led to the following conclusions:

(a) For Al-type lines, the lowest energy values were obtained for the lowest generation voltage, while the energy increases with the increase in the voltage. The relation is not linear and is not observed for all the values of $d$. The energy

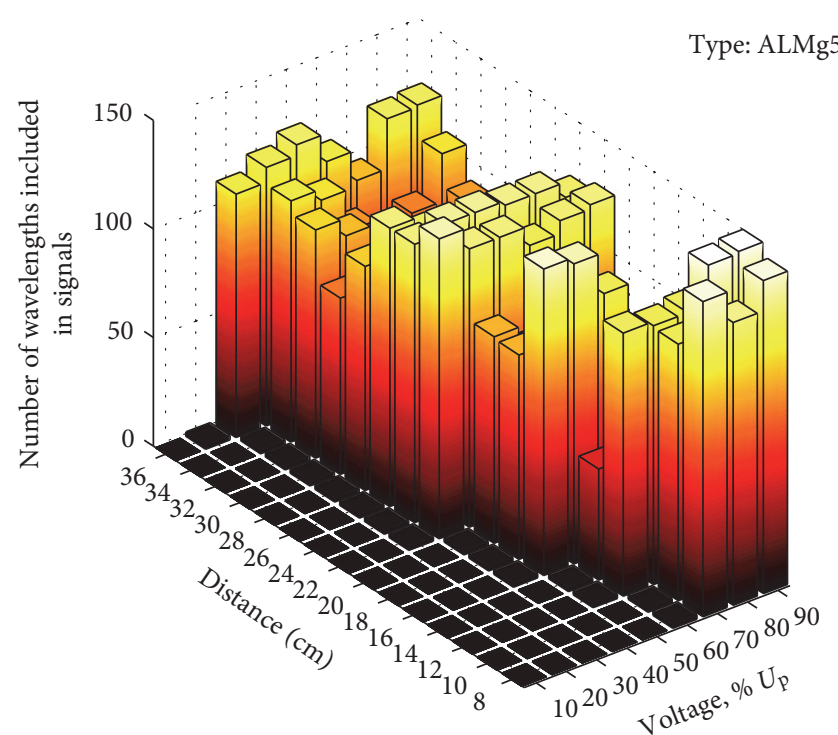

Figure 10: Dependency of voltage and distance on the number of wavelength components for the AlMg5 line.

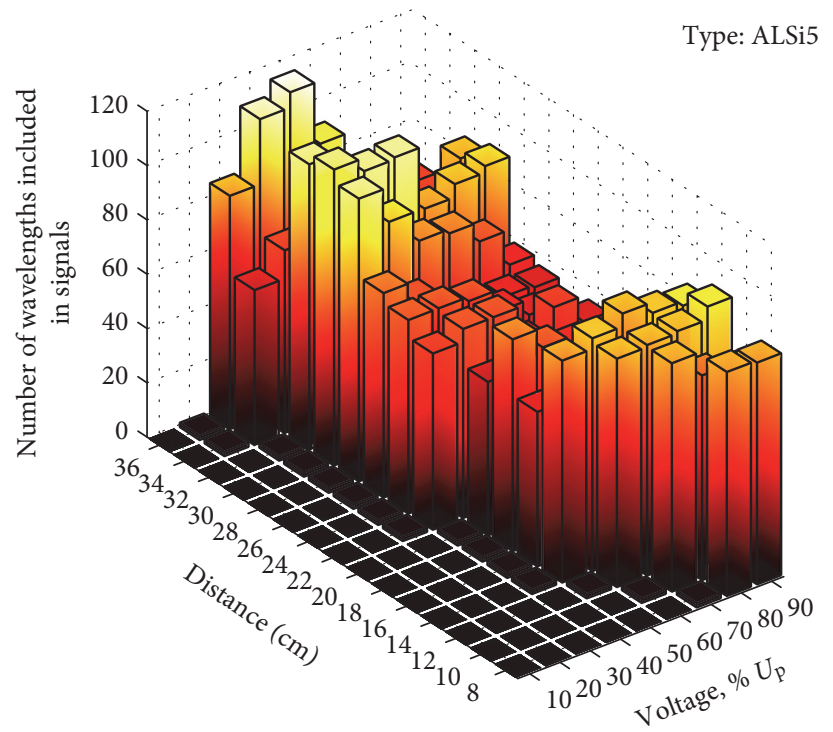

FIGURE 11: Dependency of voltage and distance on the number of wavelength components for the AlSi5 line.

remains at the constant level for the lowest values of generation voltage and is the same for all the distances. For the highest values of corona discharge generation voltage, there was no linear dependency on distance $d$ found. The highest values of energy, over $3 \mathrm{e}^{6}$, were obtained for distance $d=28 \mathrm{~cm}$ and $\% U$ in the range $20-50$.

(b) For AlMg5-type lines, the lowest energy values were obtained for the lowest generation voltage, while the energy increases with the increase in the voltage. The relation is not linear and is not 


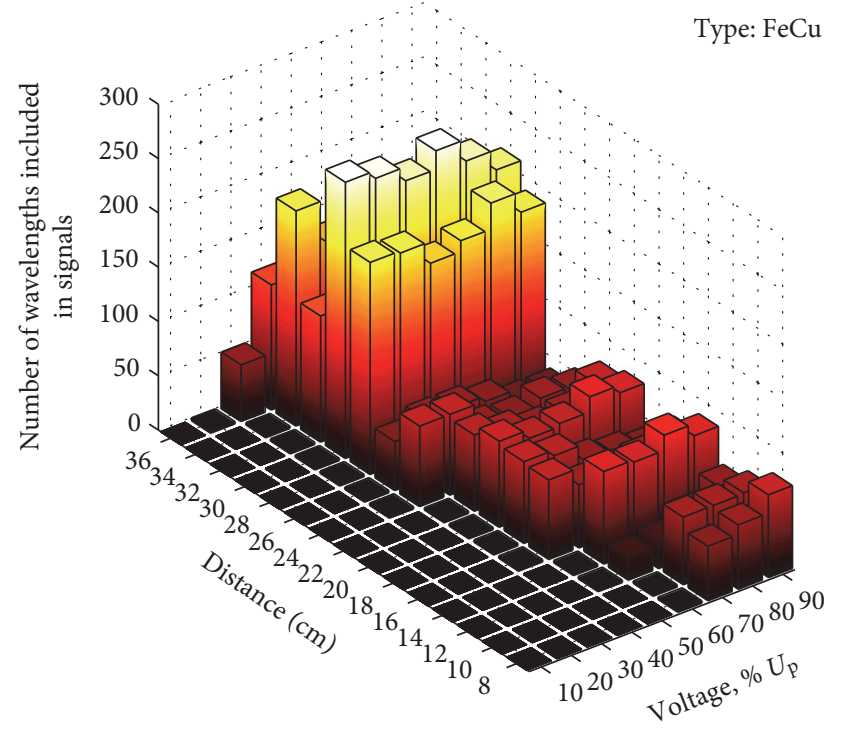

FIGURE 12: Dependency of voltage and distance on the number of wavelength components for the $\mathrm{FeCu}$ line.

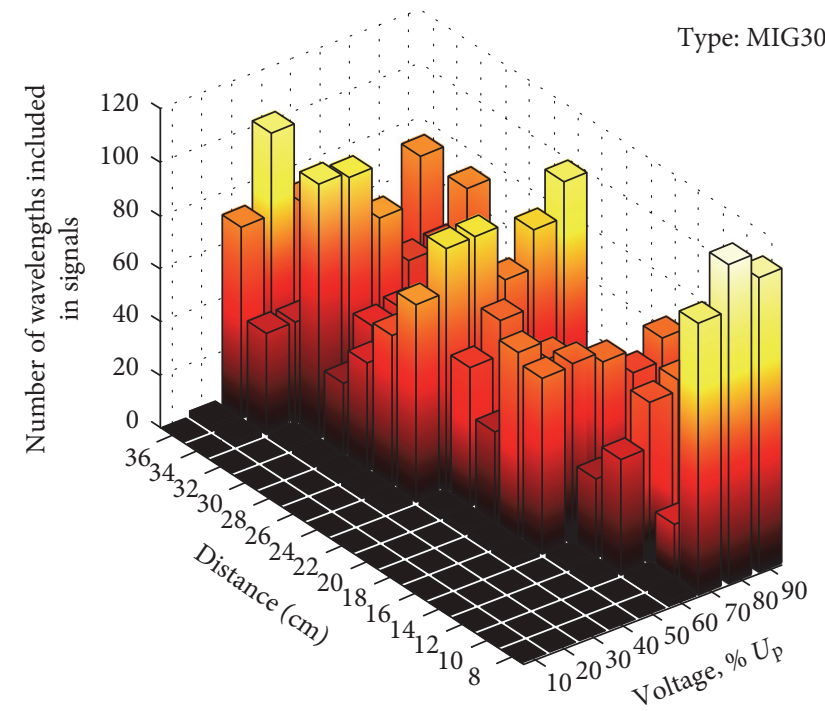

FIGURE 13: Dependency of voltage and distance on the number of wavelength components for the MIG308LSi line.

observed for all the values of $d$. The energy remains at the constant level for the lowest values of generation voltage and is the same for all the distances. For the highest values of corona discharge generation voltage, there was no linear dependency from distance $d$ found. The highest values of energy, over $2.5 \mathrm{e}^{6}$, were obtained for distances $d=\{8,10,16,22,24,26\} \mathrm{cm}$.

(c) For AlSi5-type lines, the lowest energy values were obtained for the lowest generation voltage, while the energy increases with the increase in the voltage. The relation is not linear and is not

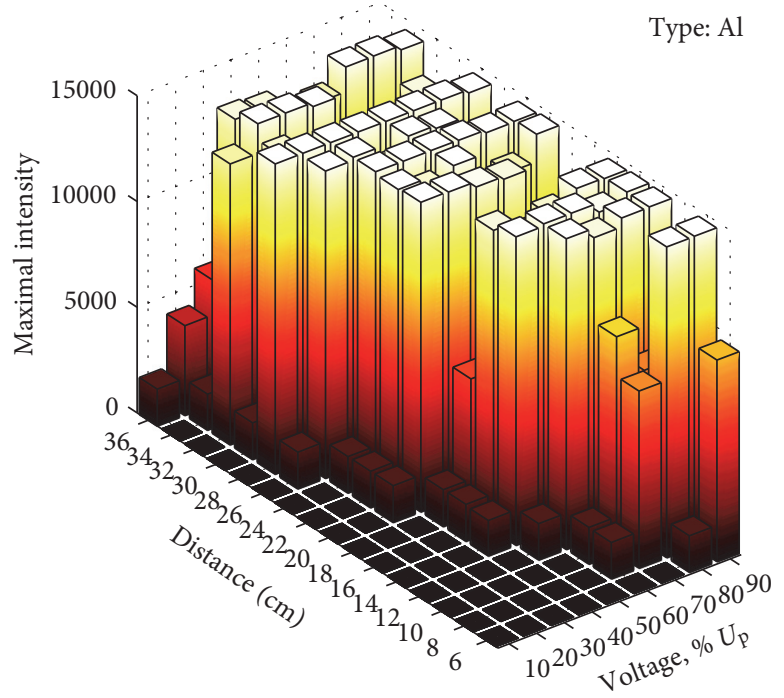

Figure 14: Dependency of voltage and distance on the highest intensity value for the $\mathrm{Al}$ line.

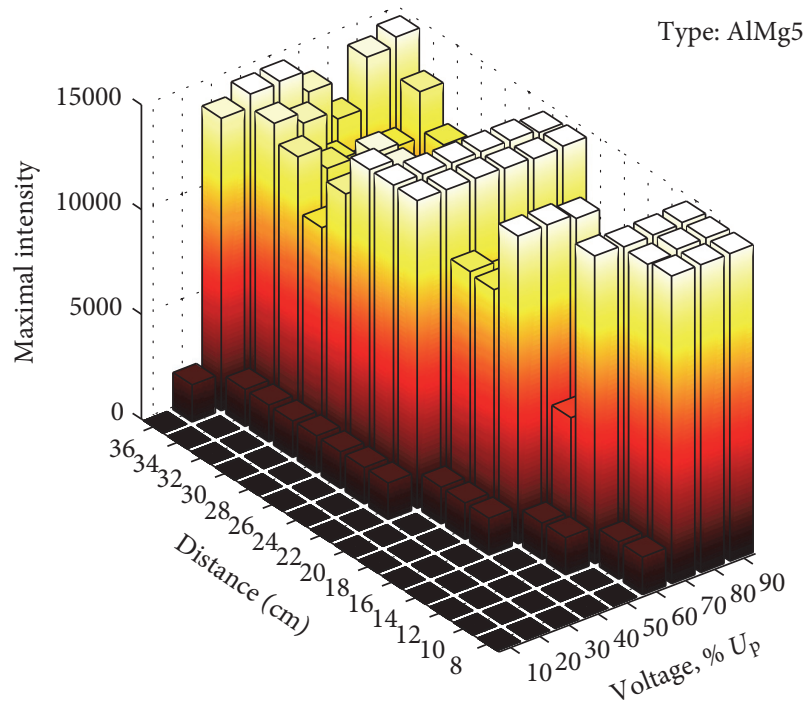

FIgURE 15: Dependency of voltage and distance on the highest intensity value for the AlMg5 line.

observed for all the values of $d$. The energy remains at the constant level for the lowest values of generation voltage and is the same for all the distances. For the higher and the highest corona discharge generation voltage, the energy remains at the same level of approx. $2 \mathrm{e}^{6}$ for a distance of $8-26 \mathrm{~cm}$ and increases in the range $d=\{28-35\} \mathrm{cm}$ for the voltage range of $30-60 \% U_{\mathrm{p}}$.

(d) For FeCu-type lines, the lowest energy values were obtained for the lowest generation voltage, while the energy increases with the increase in 


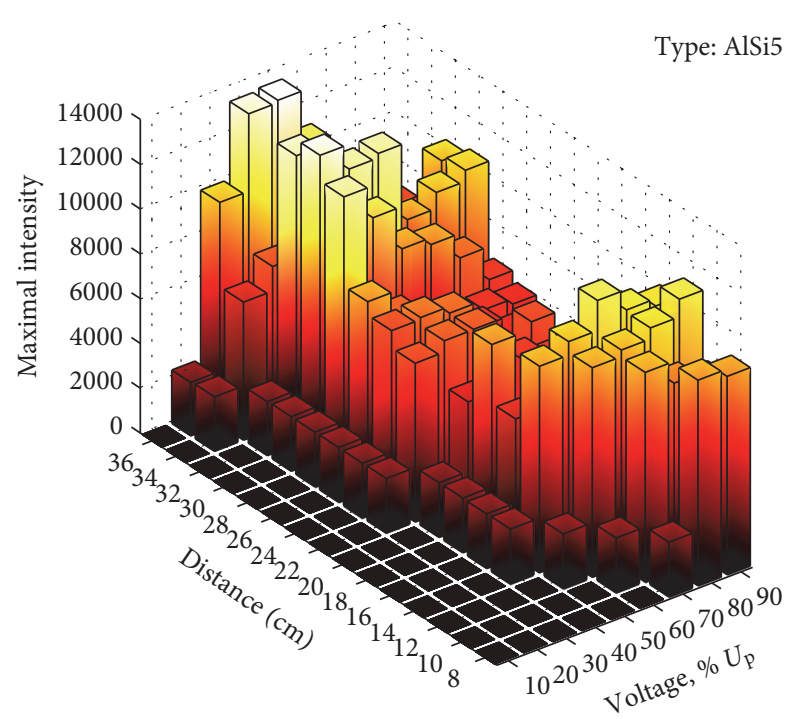

Figure 16: Dependency of voltage and distance on the highest intensity value for the AlSi5 line.

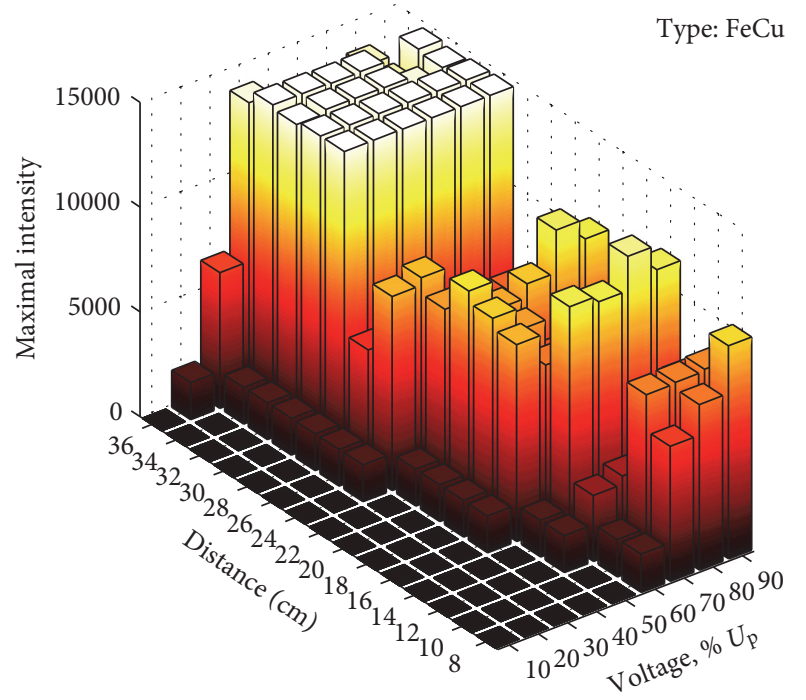

Figure 17: Dependency of voltage and distance on the highest intensity value for the $\mathrm{FeCu}$ line.

the voltage. For the higher and the highest corona discharge generation voltage, the energy remains at the same level of approx. $2-2.5 \mathrm{e}^{6}$ for a distance of $8-26 \mathrm{~cm}$ and increases significantly in the range $d=28-35 \mathrm{~cm}$ for voltages exceeding $30 \% U_{\mathrm{p}}$, reaching the value of $4 \mathrm{e}^{6}$.

(e) For MIG308LSi-type lines, the lowest energy values were obtained for the lowest generation voltage, while the energy increases with the increase in the voltage. For the higher and the highest corona discharge generation voltage, the energy remains at the same level of approx.

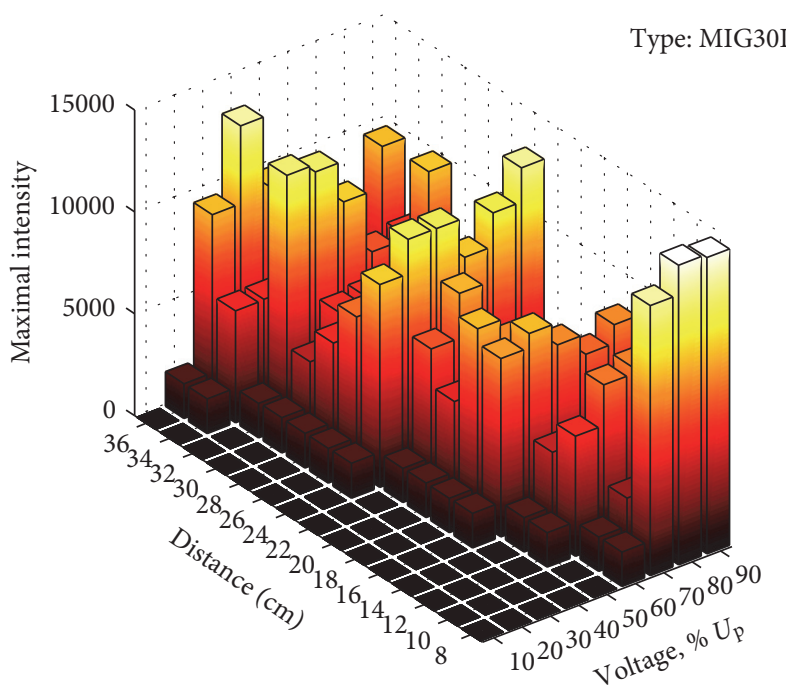

FIgURe 18: Dependency of voltage and distance on the highest intensity value for the MIG308LSi line.

$2 \mathrm{e}^{6}$. The highest values reaching $2.5 \mathrm{e}^{6}$ were obtained for distances $d=\{8,24,35\} \mathrm{cm}$.

(iii) An analysis was performed showing the number of components of the highest intensity values in the spectra recorded during measurements for the used line types as a function of distance $d$ and corona generation voltage $\% U_{\mathrm{p}}$. The following relations were obtained for all the tested lines:

(a) There was no effect of distance and corona generation voltage on number of spectrum components with $I>1600$.

(b) The increase in distance between the power lines results in the decrease in voltage, which causes emission of spectrum with intensity $I>1600$.

(c) The number of spectrum components of intensity $I>1600$ increases gradually with the increase in corona voltage for the lower values. However, this is not a linear/monotonic relation.

(d) The highest recorded spectrum intensity was below 15000, which is due to the technical capabilities of the used spectrophotometer head.

(iv) The number of spectrum components with values $I>1600$ was presented as a function of test parameters $d$ and $\% U_{\mathrm{p}}$. A linear dependency was found between the number of spectrum components with the highest intensities, when analyzed for individual values of distances $d$ and voltages $\% U_{\mathrm{p}}$. The averaged correlation value calculated using the Pearson coefficient for individual measurement series was 7.48 .

(v) The values of the highest intensities recorded in the spectra emitted by all types of the tested lines were 
aggregated in one figure and compared taking into account their dependency on distance $d$ and voltage $\% U_{\mathrm{p}}$. This type of analysis led to the following conclusions:

(a) The highest intensity of the recorded spectra was observed for the line made of alloyed aluminium $(\mathrm{AlSi} 5, \mathrm{AlMg} 5)$ and pure aluminium (Al).

(b) The lowest intensity of the recorded spectra was found for the lines made of stainless steel designated as MIG308LSi.

(c) The distance between the lines has no linear effect on the values of the highest intensities of the recorded spectra.

\section{Summary and Future Work}

Results of comparative analyses of optical signals generated by corona discharges occurring in the vicinity of power transmission lines made of five different materials were presented in this paper. The signals were registered with spectrophotometry under laboratory conditions by determining the influence of additional parameters, as corona generation voltage and distance between power lines, on the achieved results.

The conducted analysis showed differences in the intensities of corona discharge occurrence for power transmission lines made of different materials. The highest signal intensity measured with a spectrophotometer was found for aluminium-based lines, for both pure aluminium and aluminium with added magnesium and silicon. This was due to the intensive cable corrosion caused by the corona discharge and deposition of strongly hygroscopic aluminium oxides at the cable surface. The corrosion affects smoothness of the cables. Its deterioration increases occurrence of corona discharges, which in turn leads to increased corrosion. Thus, it may be concluded that there is a positive feedback loop leading to the deterioration of the power line. In general, the lowest corona intensity was observed for chromiumand nickel-alloyed steel. After all the experiments, it was also found that the stainless steel power lines had almost no signs of corrosion, which enables the assumption that the surface of the cable remained equally smooth by all measurement series.

The results obtained in the studies may help to improve diagnostics of power lines, particularly the effect of corrosion on corona discharge occurrence.

In the future work, it seems reasonable to test the effect of cable smoothness on corona discharge occurrence, including the determination of the effect of contamination on corona discharge generation and emission, particularly for older lines. It is possible to conduct ageing tests of cables and accessories used in the power lines. Under laboratory conditions, one can determine which of the factors present during the line operation are particularly dangerous. Such studies may be also conducted as a comparison for various real cables used for the construction of power lines.

\section{Conflicts of Interest}

The authors declare that there is no conflict of interests regarding the publication of this paper.

\section{Acknowledgments}

The work was cofinanced by the European Regional Development Fund "Increase of Scientific Research and Innovation for Enterprises in Terms of Sustainable Development through the Creation of a Modern Diagnostics Laboratory of Surge Voltage at the Opole University of Technology"-Part I (2010-2011) and Part II (2011-2013), Project nos. RPO.01.03.0101-16007/10-00 and WND-RPOP.01.03.01-16-007/10.

\section{References}

[1] B. Florkowska, M. Florkowski, J. Roehrich, and P. Zydron, "Partial discharge mechanism in non-homogenous electric field at higher pressure," Proceedings of International Conference on High Voltage Engineering and Application, pp. 326-330, 2008.

[2] M. Z. Fortes, V. H. Ferreira, and R. Zanghi, "Fault diagnosis in transmission lines: trends and main research areas," IEEE Latin America Transactions, vol. 13, no. 10, pp. 3324-3332, 2015.

[3] A. R. Adly, R. A. El Sehiemy, A. Y. Abdelaziz, and N. M. A. Ayad, "Critical aspects on wavelet transforms based fault identification procedures in HV transmission line," IET Generation Transmission Distribution, vol. 10, no. 2, pp. 508-517, 2016.

[4] J. Bajorek, G. Maslowski, and R. Ziemba, "Identification of corona parameters on overhead power lines in case of direct lightning strikes," Proceedings of International Conference on High Voltage Engineering and Application, pp. 69-72, New Orleans, USA, 2010.

[5] M. Brahami, A. Gourbi, A. Tilmatine, and L. Dascalescu, "Numerical analysis of the induced corona vibrations on highvoltage transmission lines affected by rainfall," IEEE Transactions on Power Delivery, vol. 26, no. 2, pp. 617-624, 2011.

[6] D. Dib and A. Daas, "Influence of atmospheric conditions on the corona effect in HV power systems," Proceedings of 16th International Power Electronics and Motion Control Conference and Exposition, pp. 628-634, Antalya, Turkey, 2014.

[7] Y. P. Liu, H. Bin Wang, W. J. Chen, Y. J. Yang, and T. Jian, "Test study on corona onset voltage of UHV transmission lines based on UV detection," Proceedings of International Conference on High Voltage Engineering and Application, pp. 387-390, Chongqing, China, 2008.

[8] D. K. Mohanta, P. Gopakumar, and M. J. B. Reddy, “Transmission line fault detection and localisation methodology using PMU measurements," IET Generation Transmission Distribution, vol. 9, no. 11, pp. 1033-1042, 2015.

[9] M. Shen, J. Wu, and Y. Yin, "Experimental investigating on online monitoring of insulation system of power transformers," Proceedings of Conference on Electrical Insulation and Dielectric Phenomena, pp. 327-330, Chenzhen, China, 2013.

[10] P. Wang and G. Zhang, "The measurement method for corona discharge current under high-voltage environment," IEEE Transactions on Instrumentation and Measurement, vol. 57, no. 8, pp. 1786-1790, 2008.

[11] X. Bian, L. Chen, D. Yu, L. Wang, and Z. Guan, "Impact of surface roughness on corona discharge for 30-year operating conductors in $500-\mathrm{kV}$ ac power transmission line," IEEE 
Transactions on Power Delivery, vol. 27, no. 3, pp. 16931695, 2012.

[12] M. Ma, Y. Zhao, Z. Guan, and L. Wang, "The influence of contaminations on HVDC conductor corona characteristics," Proceedings of Conference on Electrical Insulation and Dielectric Phenomena, pp. 537-541, Vancouver Bc, Canada, 2007.

[13] P. Frącz, "System for monitoring partial discharges occurring in overhead power transmission line insulators based on ultraviolet radiation registration," Insight, vol. 58, no. 7, pp. 360-366, 2016.

[14] P. Fracz, T. Boczar, S. Borucki, A. Cichoń, and D. Zmarzly, "Results of optical signals analyses emitted by electrical discharges recorded with UV camera," Acta Physica Polonica $A$, vol. 122, no. 5, pp. 814-817, 2012.

[15] P. Fracz, T. Boczar, D. Zmarzly, and T. Szczyrba, "Analysis of optical radiation generated by electrical discharges on support insulator," Acta Physica Polonica A, vol. 124, no. 3, pp. 413-416, 2013.

[16] P. Frącz, I. Urbaniec, T. Turba, and S. Krzewiński, "Diagnosis of high voltage insulators made of ceramic using spectrophotometry," Journal of Spectroscopy, vol. 2016, Article ID 9548302, p. 16, 2016.

[17] P. Frącz, I. Urbaniec, and J. Foltys, "Comparison of two methods for detection of UV signals emitted by PD on HV insulator made of porcelain," Przegląd Elektrotechniczny, vol. 92, no. 8, pp. 102-104, 2016. 

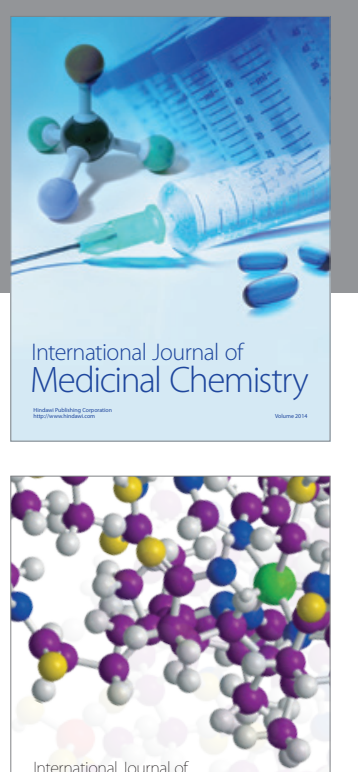

Carbohydrate Chemistry

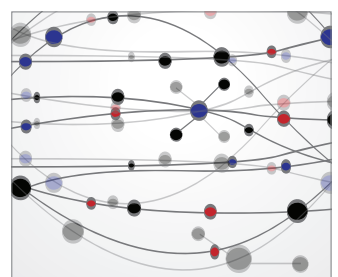

The Scientific World Journal
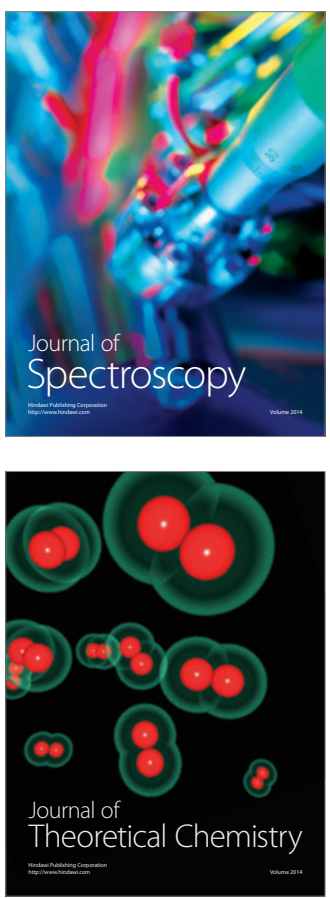
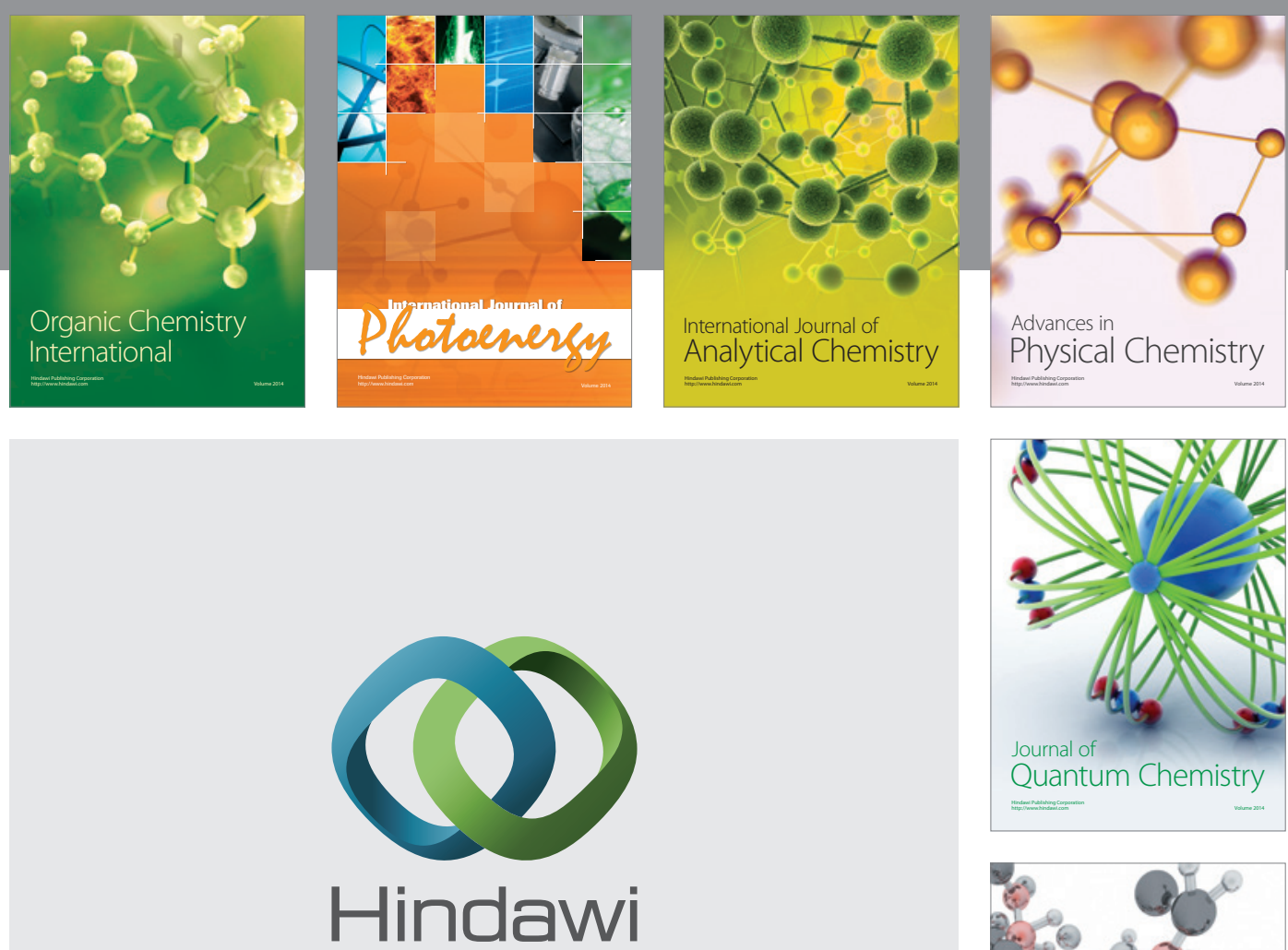

Submit your manuscripts at

https://www.hindawi.com

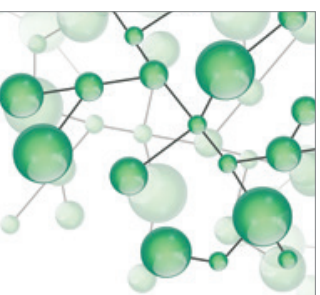

International Journal of

Inorganic Chemistry
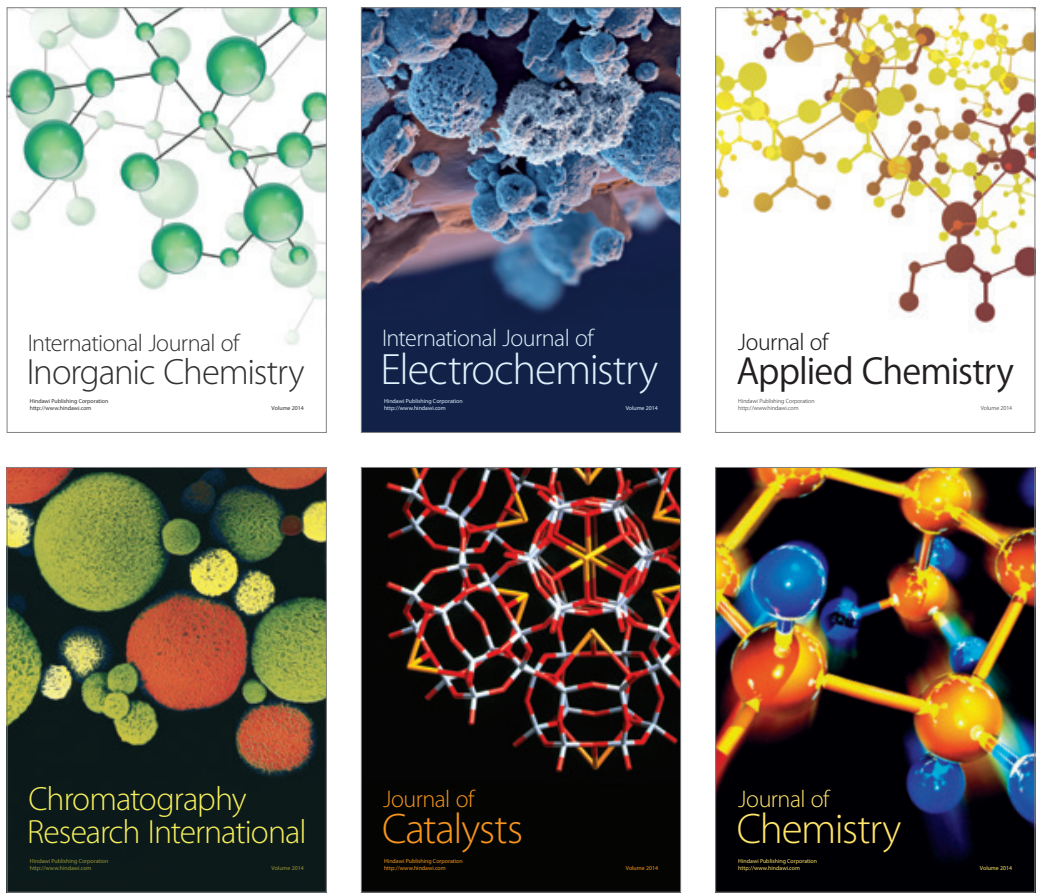

Journal of

Applied Chemistry
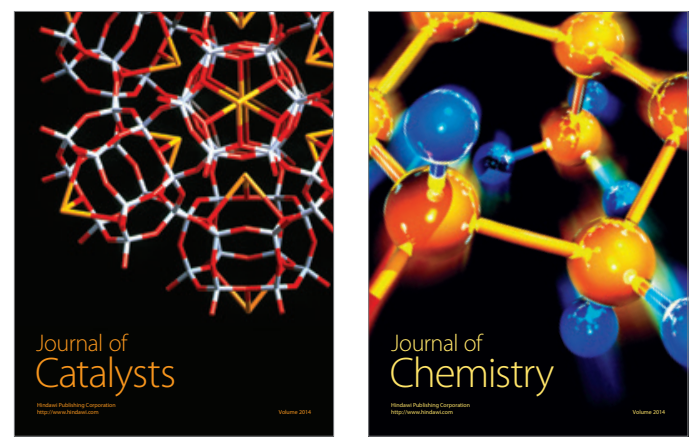
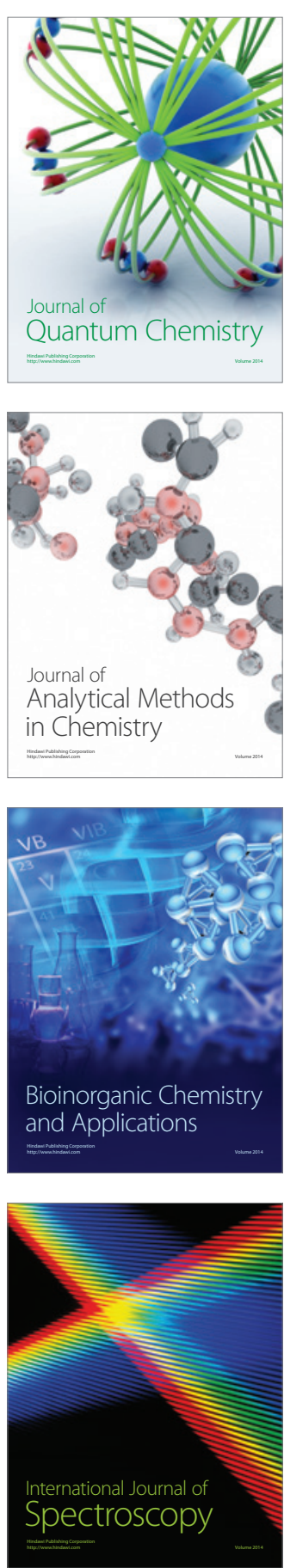